\title{
Green Synthesis of Copper Nanoparticles Using Syzygium Cumin, Leaf Extract, Characterization and Antimicrobial Activity
}

\author{
H. R. AHER ${ }^{1}$, S. H. HAN ${ }^{2}$, A. S. VIKHE ${ }^{3}$ and S. R. KUCHEKAR ${ }^{3}$ \\ ${ }^{1}$ Department of Chemistry, P.V.P. College, Pravaranagar, India \\ ${ }^{2}$ Inorganic Nanomaterial Laboratory, Department of Chemistry, Hanyang University, \\ Seoul, South Korea \\ ${ }^{3}$ Department of Food Science, Women's College of Home Science and BCA, Loni, \\ Tal-Rahata, Dist-Ahmednagar, (MS), 413713, India \\ shashi17@gmail.com
}

Received 31 May 2018 / Accepted 15 June 2018

\begin{abstract}
The use of plant material for synthesis of nanoparticles is a green technology. This green technique was used for synthesis of copper nanoparticles by biologically reducing copper sulphate solution with aqueous Syzygium Cumin leaf extract at $\mathrm{pH}$ 5.0. The formation of copper nanoparticles was indicated by the colour change from yellow to brown. The UV-Visible spectrum of copper nanoparticles gave surface Plasmon resonance (SPR) of $190 \mathrm{~nm}$. The synthesized nanoparticles were characterized using scanning electron microscopy (SEM), x-ray, diffraction (XRD) and FTIR, These biologically synthesized copper nanoparticles were tested for antimicrobial activity against human pathogens viz. Bacillus subtilis and E-coli. Presence of elemental copper was revealed by EDAX. These biologically synthesized copper nanoparticles were found to be effective in controlling growth of human pathogens viz., Bacillus subtilis and E-coli.
\end{abstract}

Keywords: Syzygium cumini, SEM, XRD, EDAX, FTIR, UV-Vis, Bacillus subtilis and E-coli

\section{Introduction}

Nanoscience and nanotechnology include the areas of synthesis, characterization, exploration, application of nanostructure and nanosize materials ${ }^{1}$. Nanoparticles have been extensively studied over the last decade due to its characteristics like chemical, physical, electronic, electrical, mechanical, magnetic, thermal, dielectric, optical and biological properties $^{1}$. In recent years, the biocidal properties of copper nanoparticles (CuNPs) have wide application in treating wounds. CuNPs are used through processed bandages with affordable cost of preparation as well as exceptional physical and chemical properties ${ }^{2,3}$. Preparation of nanoparticle is primarily based on their smaller size and their high surface to volume ratio. Now a day's metal and metal oxide nanoparticles are receiving increasing attention in a large variety of application. They have industrial usage such as gas sensors, 
Chem Sci Trans., 2019, 8(1), 1-6

solar cells, catalytic processes etc., ${ }^{4,5}$. Several methodologies have been proposed with interesting approaches to control the nonmaterial properties such as size and shape, these include metal vapor co-deposition, electrochemical reduction, gas phase evaporation method, thermal decomposition, radiolytic reduction and chemical reduction etc., ${ }^{6,7}$. Although various physical and chemical methods have been extensively used to produce nanosized copper particle such as micro-emulsion method $^{8}$ arc submerged. Nanoparticle synthesis system ${ }^{9}$, flame based aerosol methods ${ }^{10}$, sonochemical ${ }^{11}$, hydrothermal ${ }^{12}$ and solid state techniques ${ }^{13}$. The use of toxic chemicals for the synthesis of nanoparticle limits their applications in clinical fields. Therefore, developments of clean, biocompatible, nontoxic and eco-friendly methods for nanoparticles synthesis are advantageous. The interest in this field has shifted toward 'green' chemistry and bio-processor approach. These approaches focus on utilization of environmental-friendly, cost-effective and biocompatible reducing agents for synthesis of copper nanoparticles from various plant extracts have been utilized in the synthesis of nanoparticles. Ascorbic acid present in the Syzygium cumin leaves extract is a good reducing and capping agent and aids in the biosynthesis of copper nanoparticles ${ }^{14}$. In this communication we are reporting biomaterial assisted synthesis of copper nanoparticles, reducing the copper ions by the aqueous extract of Syzygium cumin leaf extract.

\section{Experimental}

$0.1 \mathrm{M}$ solution of copper sulphate pentahydrate was prepared by dissolving $2.497 \mathrm{~g}$ salt in distilled water and diluted to $100 \mathrm{~mL}$ with distilled water.

\section{Preparation of leaf extract}

The fresh leaves of Syzygium cumin were thoroughly washed with normal water and then followed by distilled water to remove the impurities. The cleaned leaves were kept under sun shade to remove moisture completely and subsequently transferred to $100 \mathrm{~mL}$ beaker containing distilled water and allow to boil at $100{ }^{\circ} \mathrm{C}$ for $30 \mathrm{~min}$. Then cool it to room temperature. This solution was initially filtered through ordinary filter paper and then by Whatman No.1 filter paper to get clear extract. This solution was diluted to $100 \mathrm{~mL}$ with distilled water. The filtrate was stored at room temperature for use.

\section{Green synthesis of copper nanoparticle using leaves extract}

The leaf extract about $10 \mathrm{~mL}$ was introduced drop wise into $100 \mathrm{~mL}$ of $0.1 \mathrm{M}$ solution of $\mathrm{CuSO}_{4} 5 \mathrm{H}_{2} \mathrm{O}(0.025 \mathrm{~g} / \mathrm{mL})$ under continuous stirring with help of magnetic stirrer. After the complete addition of leaf extract, the mixture was kept for incubation for $24 \mathrm{~h}$ within a particular time; the green colour of extract was changed into dark green, (Figure 1) which indicates the formation of copper nanoparticles. Then supernatant was removed and nanoparticles containing extract was transferred to silica crucible and kept in oven at $99{ }^{\circ} \mathrm{C}$ then temp was increased to $300-400{ }^{\circ} \mathrm{C}$. These particles were analysed using FTIR, SEM and EDAX.

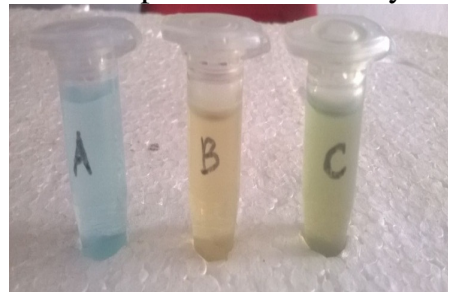

Figure 1. Synthesis of copper nanoparticle A-Cu solution, B-leaf extract, C-Cu solution + leaf extract 


\section{Results and Discussion}

\section{UV-Visible studies}

The reduction of copper ions to copper nanoparticles was monitored by recording UV-Visible spectrum of the reaction mixture after diluting a small aliquot of the sample with distilled water. The measurements were recorded on Systronics Au-2701 model UV-Visible dual beam spectrometer operated at resolution $(190-900 \mathrm{~nm})$ giving maxima at $190 \mathrm{~nm}$ (Figure 2).

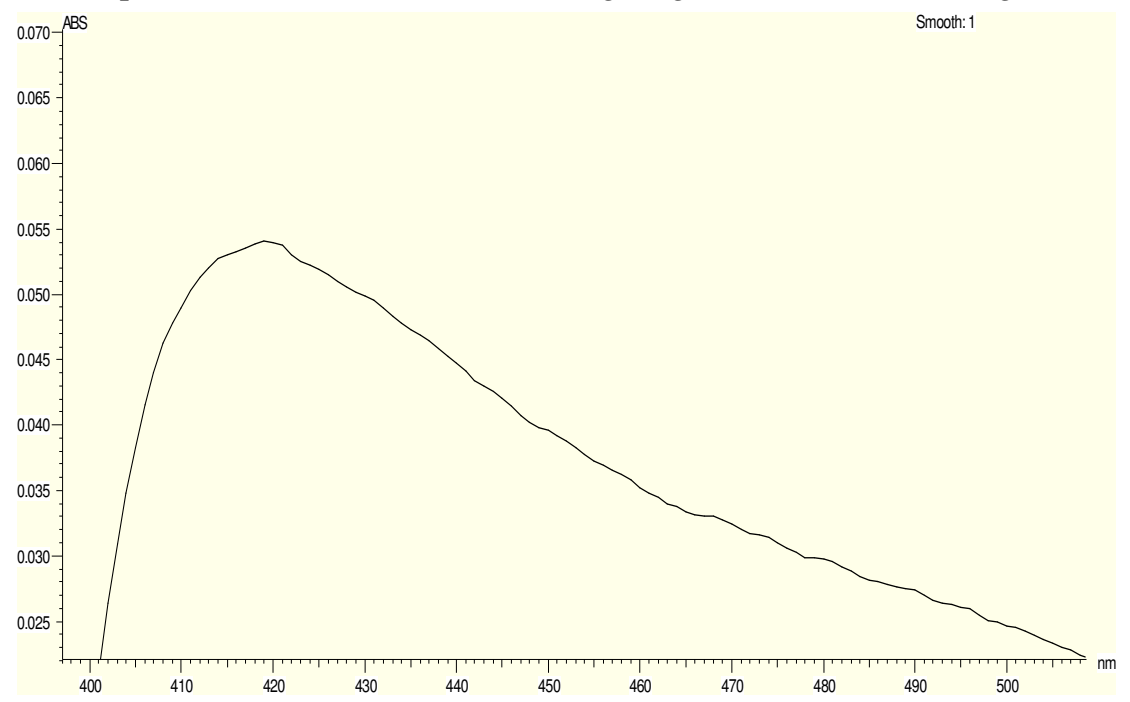

Figure 2. UV-Visible spectra of synthesized CuNP

\section{Fourier transform-Infrared (FT-IR)}

The FTIR spectrum was taken to identify and characterize the molecule and their functional group present in synthesized CuNPs are shown in (Figure 3), $\mathrm{CuO}$ and $\mathrm{Cu}_{2} \mathrm{O}$ vibrational modes are observed ${ }^{15}$ at $605.65 \mathrm{~cm}^{-1}$.

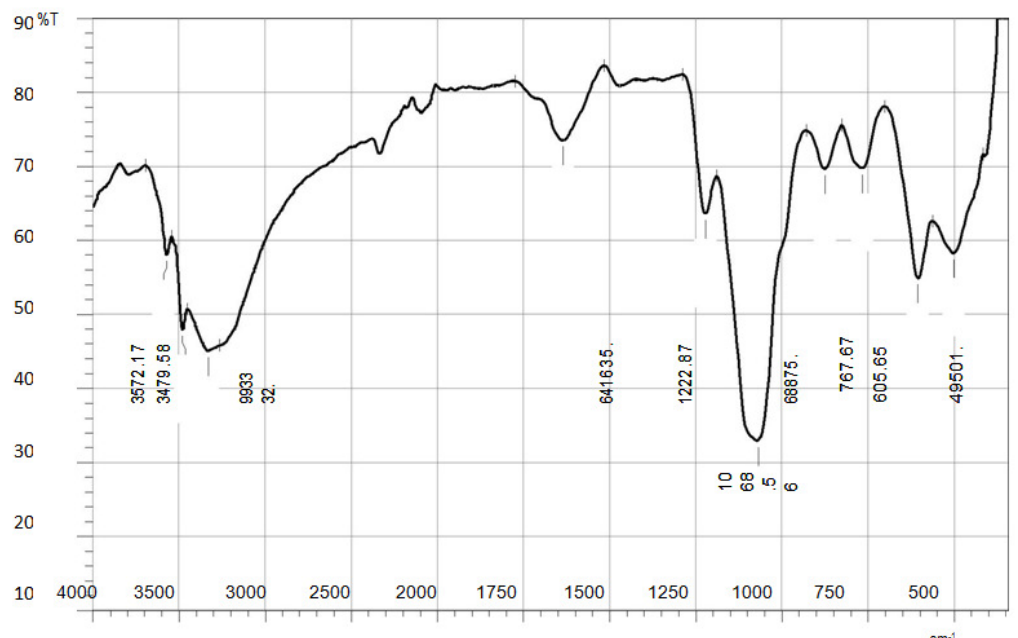

Figure 3. FTIR spectrum of synthesized CuNPs 


\section{$X$-Ray diffraction studies}

X-ray diffraction (XRD) measurement of the copper nanoparticles is shown in Figure 4. Spectrum was taken using powder x-ray diffractometer instrument. The crystallite domain size was calculated by using Debye-Scherrer formula. The sample of CuNPs demonstrated a high crystalinity level with diffraction angles of $34.3,35.3,38.6,48.2$ and which related to monoclinic end centered with space group C2/c (15) of copper lines indexed at (023), (111), (111) ) and (202).

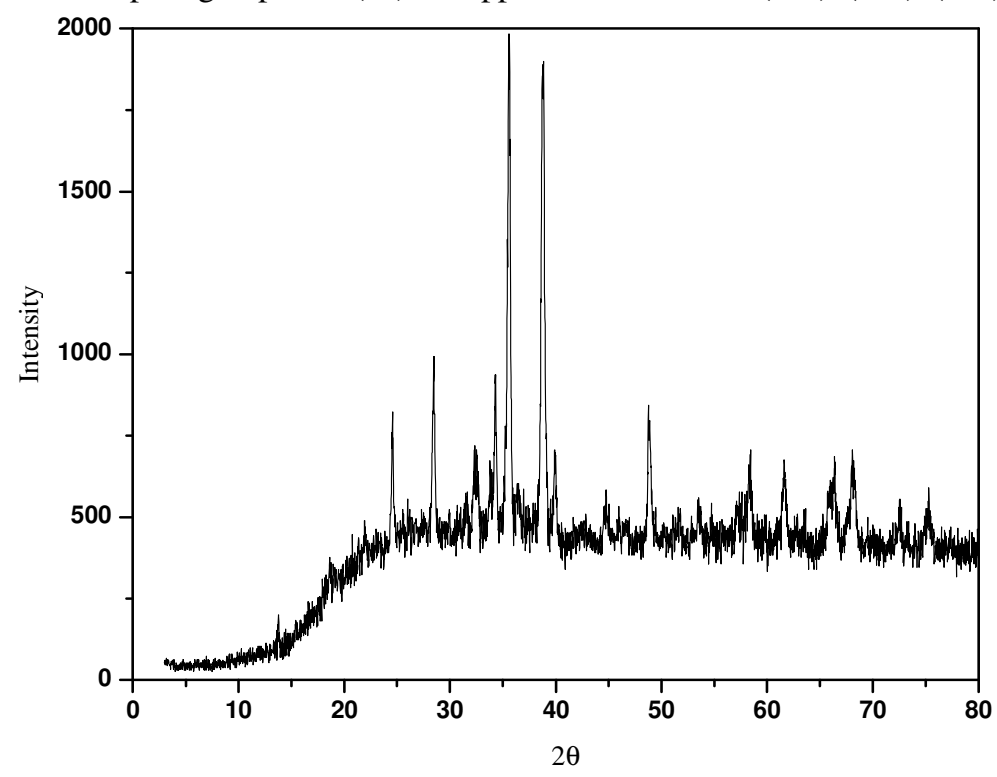

Figure 4. XRD analysis of copper nanoparticles

\section{Scanning electron microscopic analysis}

Scanning electron microscopic (SEM) analysis was carried out using S-4800, serial numberHI-9143-004 SEM machine. Thin films of the sample were prepared on a carbon coated copper grid by just a very small amount of the sample on the grid, extra sample was removed using a blotting paper and then the film on the SEM grid were allowed to dry by putting it under a mercury lamp for $5 \mathrm{~min}$. SEM Agglomeration of the $\mathrm{Cu}$ nanoparticles observed and average particle size is around $10 \mu \mathrm{m}$ each.

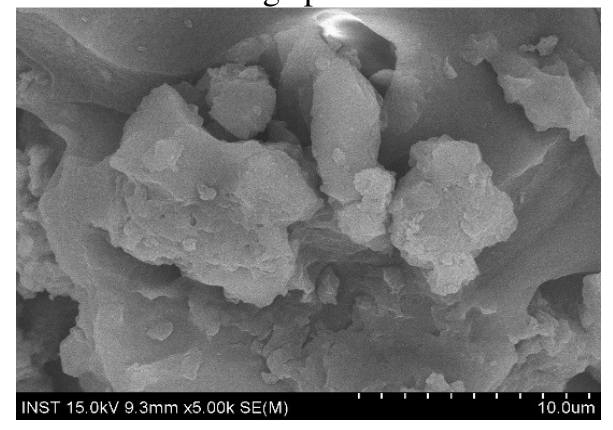

a

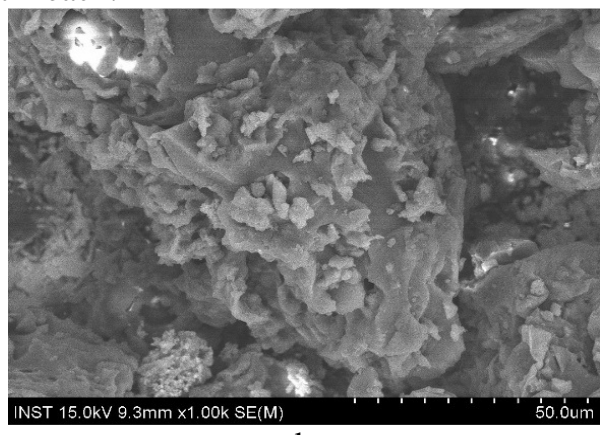

$\mathrm{b}$

Figure 5. SEM images of copper nanoparticles (a) $10 \mu \mathrm{m}$ (b) $50 \mu \mathrm{m}$ 


\section{EDAX}

The composition of copper nanoparticles was further probed by energy-dispersive X-ray (EDX) analysis. Figure 6 shows the EDX pattern of CuNPs obtained from plant extract, which indicates the presence of $\mathrm{Cu}$ and small amount of oxygen. Energy dispersive $\mathrm{X}$-ray spectroscopy (EDX) analysis revealed that pure copper (39.16\%) was present in CuNPs.
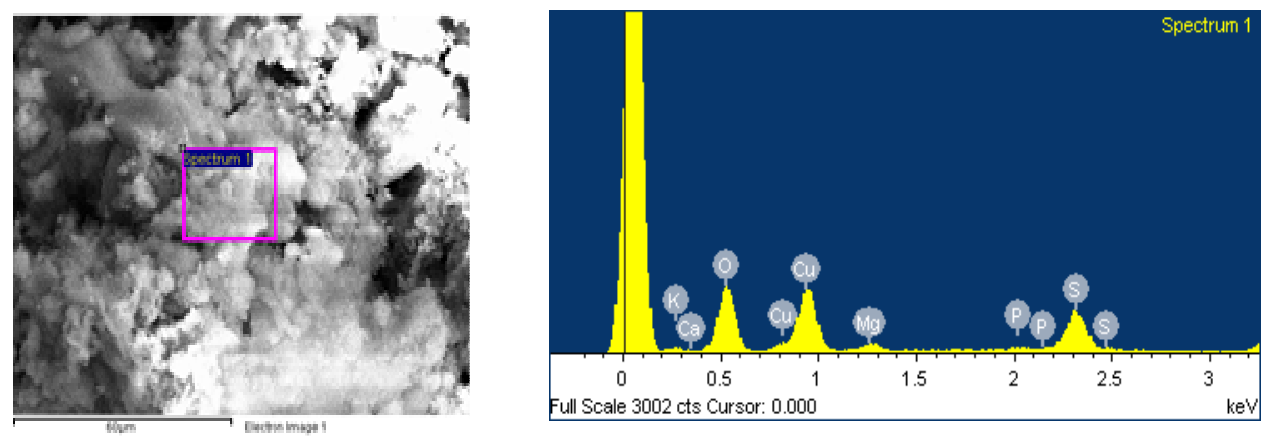

\begin{tabular}{ccc}
\hline Element and series & Weight \% & Atomic \% \\
\hline OK & 38.81 & 65.5 \\
$\mathrm{Mg} \mathrm{K}$ & 2.61 & 2.40 \\
$\mathrm{P} \mathrm{K}$ & 0.54 & 0.47 \\
$\mathrm{~S} \mathrm{~K}$ & 9.59 & 8.10 \\
$\mathrm{~K} \mathrm{~K}$ & 7.15 & 4.95 \\
$\mathrm{Ca} \mathrm{K}$ & 2.59 & 1.75 \\
$\mathrm{Cu} \mathrm{L}$ & 39.16 & 16.68 \\
\hline Total & 100.00 & \\
\hline
\end{tabular}

\section{Antimicrobial activity}

Figure 6. EDX spectrum

The antimicrobial activity of pathogens was established using well diffusion method. The bactericidal effect of copper nanoparticles has been attributed to their high surface to volume ratio and small size which allows them to interact very closely with microbial membranes. The antimicrobial study of CuNPs was carried out using two pathogenic bacteria such as E-coli and bacillus subtilis. To cultivate the bacteria, nutrient agar was used. About $20 \mathrm{~mL}$ of sterile molten agar was poured into the sterile Petri dishes. After solidification of medium, the Petri dishes were placed on the solidified medium. Then copper nanoparticles with $600 \mu \mathrm{L}$ concentration was prepared. $40 \mu \mathrm{L}$ concentration were added into the one of the well of Petri dishes. Petri dishes were incubated for $24 \mathrm{~h}$ at $37^{\circ} \mathrm{C}$. Antibacterial capacity of the copper nanoparticles was measured by standard zone of inhibition assay (Figure 7).

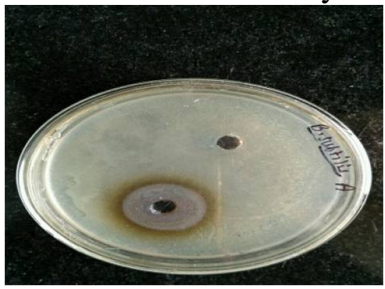

(a) Bacillus subtilis

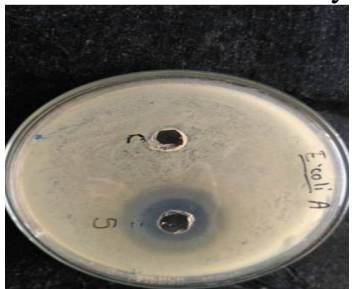

(b) E-coli

Figure 7. Antimicrobial activity of CuNPs 


\section{Acknowledgment}

Authors are thankful to the Management PRESS, Loni and Principal, Womens College of Home Science and BCA, Loni for providing necessary facilities in department.

\section{References}

1. Michael L Roukes, Understanding of nanotechnology, Warner Books, Scientific American Inc.,Newyork, 2002; ISBN: 978-0-7595-2746-1.

2. Bargali J, Bargali S S, Singh L, Ghosh L and Lakhera M L, Curr Sci., 2009, 96(4), 581-587.

3. Parihaar J, Bargali R S and Bargali S S, Indian J Agr Sci., 2015, 85(3), 442-447.

4. Unruh J D and Lefebvre P A, Agrofor Syst., 1995, 32(1), 81-96; DOI:10.1007/BF00713850

5. Pathak J, Pateria P S, H M and Solanki K R, Agroforestry Systemsin India: A Diagnosis and Design Approach, NRCAF (ICAR), New Delhi, 2000.

6. $\quad$ Lin H, Wang C, Shih H C, Chen J and Hsieh J, J Appl Phys., 2004, 95(10), 58895895; DOI:10.1063/1.1690114

7. Zhang J J, Liu J F and Li Y D, Chem Mater., 2006, 18(4), 867-871; DOI:10.1021/cm052256f

8 Nasser N N and Husein M M, J Colloid Interfsci., 2007, 316(2), 442-450; DOI:10.1016/j.jcis.2007.08.044

9. Kao M J, Lo C H, Sang T T, Wu Y Y, Jwo C S and Lin H M, J Alloy Compd., 2007, 434-436, 672-674; DOI:10.1016/j.jallcom.2006.08.305

10. Chiang C Y, Aroh K and Ehrman S N, 2012, Int J Hydrogen Energy, 2012, 37, 4871-4879.

11. Vijayakumar R, Elgamiel R, Dimant Y, Gedanken A and Norwig J, Langmuir, 2001, 17(5), 1406-1410.

12. Zhang Y, Wang S, Xuebing Li, Liyong C, Yitai Qian and Zude Zang, J Cryst Growth, 2006, 291(1), 196-201; DOI:10.1016/j.jcrysgro.2006.02.044

13. Wang J, Yang J, Sun J, Bao Y, Mater Des., 2004, 25(7), 625-629; DOI:10.1016/j.matdes.2004.03.004

14. Patel B H, Channiwala M Z, Chaudhari S B and Mandot A A, J Environ Chem Engg., 2016, 4(2), 2163-2169; DOI:10.1016/j.jece.2016.03.046

15. Brogohain K, Singh J B, Rama M V R, Shripathi T and Mahamuni S, Phys Rev B., 2000, 61, 11093; DOI:10.1103/PhysRevB.61.11093 